\title{
Tonic immobility in chickens: Is a stimulus that signais shock more aversive than the receipt of shock?*
}

\author{
GORDON G. GALLUP, JR. \\ Tulane University, New Orleans, Louisiana 70118
}

\begin{abstract}
Three experiments were conducted on the effect of shock and aversive conditioning on tonic immobility. In the first study: increasing the intensity of preinduction shock was shown to produce reliable increases in the duration of immobility. Using classical conditioning procedures in the second experiment, a significant effect of UCS intensity was obtained. In the third experiment, brief confrontation with a conditioned fear stimulus was found more effective than shock for enhancing immobility duration. The data were discussed in terms of the fear hypothesis of animal hypnosis and as supporting a more general notion that the anticipation of shock may be more aversive than the receipt of shock.
\end{abstract}

Tonic immobility as a response to manual restraint is a state of temporary paralysis that obtains in many different species and has been the subject of considerable speculation (e.g., Klemm, 1971; Ratner, 1967). In domestic chickens, the reaction is accompanied by periods of irregular eye closure and suppressed vocalization during the initial period of catalepsy. The legs may be flexed or extended (often exhibiting signs of catatonic-like waxy flexibility) and there are frequent leg tremors. When chicks are immobilized in the upright position, wing drooping, which resembles injury feigning, is common.

Recent work with chickens has shown that laboratory conditions designed to increase fear, such as electric shock, loud noise, and subcutaneous injections of adrenalin, tend to prolong the immobility reaction (Braud \& Ginsburg, 1973; Gallup, Nash, Potter, \& Donegan, 1970). Similarly, more naturally occurring sources of fear, such as simulated predation, also enhance the reaction (Gallup, Nash, Donegan, \& McClure, 1971), and immobility duration correlates significantly with other indices of fear, such as defecation (Gallup, Nash, \& Wagner, 1971).

On the other hand, procedures known to reduce fear (e.g., habituation, social stimulation, conditioned inhibition, and tranquilizer ingestion) serve to attenuate the duration of tonic immobility (Gallup, Nash, \& Brown, 1971; Gilman, Marcuse, \& Moore, 1950; Maser, Gallup, \& Barnhill, 1973; Salzen, 1963). Thus, stimulus manipulations known to produce directional effects on the level of fear have been shown to be important antecedent conditions for producing directional effects on the duration of immobility; whereas changes in arousal unrelated to fear (e.g., food deprivation) have not been found to effect tonic immobility (Gallup \& Williamson, 1972).

As further support for the notion that tonic immobility represents a fear-mediated reaction, Gallup, Rosen, and Brown (1972) found that a conditioned fear

*Appreciation is expressed to G. Rones, T. S. Rosen, and T. J. $\mathrm{O} B$ rien for help in data collection. stimulus prolonged the immobility episode in young chicks. In fact, the effect of conditioned fear appeared to be a more potent immobility enhancer than primary fear in the form of electric shock. For example, in the Gallup et al (1970) study, preinduction exposure to a $5.25-\mathrm{mA}$ shock for $3 \mathrm{sec}$ produced a mean immobility duration of $714.9 \mathrm{sec}$, whereas using a stimulus previously paired with a less intense shock $(3.5 \mathrm{~mA})$, the average duration of immobility was $1,343 \mathrm{sec}$ in one experiment and $1,687.3 \mathrm{sec}$ in a second (Gallup et al, 1972). The major methodological difference between these two studies was that in the earlier paper immobility was terminated by the E after $900 \mathrm{sec}$, thus creating a potential ceiling on duration. Also, in the conditioned fear study, birds received extensive habituation training prior to testing, whereas in the $\mathbf{1 9 7 0}$ study naive chicks were used.

The purpose of the present experiments was to control for these procedural differences and to compare the effect of primary fear in the form of shock, with a stimulus previously paired with shock as the means of exaggerating tonic immobility. The first experiment varied the intensity of preinduction shock administered to habituated chickens and measured the resulting duration of self-paced immobility. Using a classical conditioning paradigm, the second experiment was designed to assess the effect of UCS intensity on the duration of immobility following brief exposure to a conditioned stimulus. In the final experiment, an attempt was made to compare the effect of conditioned fear and shock on tonic immobility.

\section{EXPERIMENT I}

Using habituated chickens, the purpose of the first experiment was to vary the intensity of electric shock administered prior to imposing manual restraint.

\section{Method}

The Ss consisted of 50 straight-run Production Red chickens (Gallus gallus), obtained from a local hatchery at 1 day of age. The birds were housed in commercial brooders equipped with 


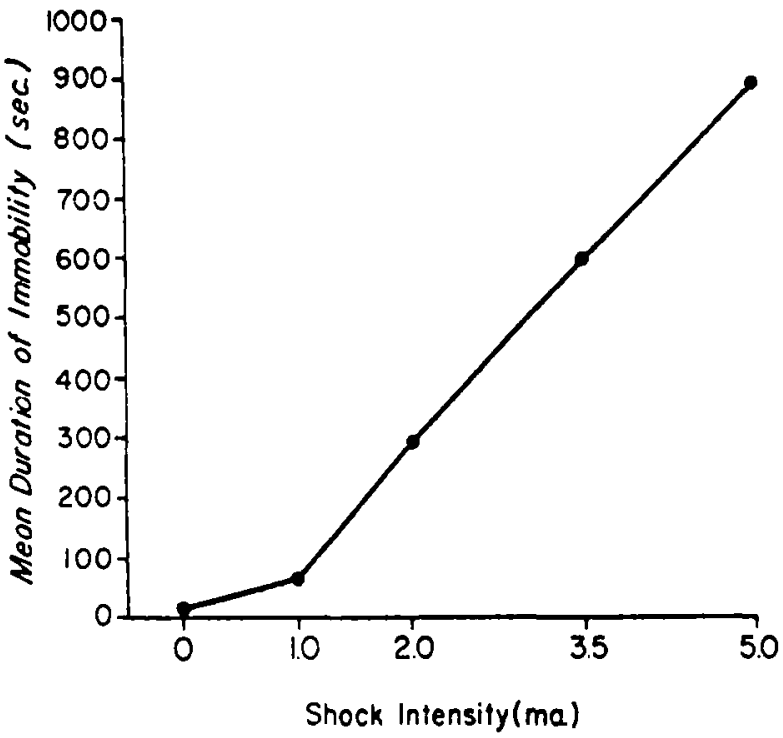

Fig. 1. Duration of tonic immobility shown by habituated chickens as a function of preinduction shock intensity.

thermostatically controlled heating elements and were given tree access to Purina chick chow (Growena) and water during rearing. The photoperiod in effect throughout was held constant. with $14 \mathrm{~h}$ of artificial light being provided each day.

At 21 days of age. the birds were all given 3 days of habituation training designed to provide for a more homogeneous group of $\mathrm{Si}$ and to preclude a possible ceiling affect of fear due to initial $\mathrm{E}$ confrontation. The rationale for using habituated birds and the mechanics of the induction prosedure are described in more detail by Gallup. Nash, and Wagner (1971). Habituation consisted of manually restraining a chick on its right side for $15 \mathrm{iec}$ in a three-sided induction bos. which measured $.61 \times .61 \times .5 \mathrm{~m}$ and was positioned on a table. The duration of each immobility response was terminated after about 60 sec by gentle prodding. and each chick was given five inductions per day. with an intertrial interval of approximately 45 sec. During each immobility episode. the $E$ sat quietly on chair about $.9 \mathrm{~m}$ away and avoided making direct eve contact with the S. Large pliwood boves, perforated with holes for ventilation. were used to transport birds to the testing site and sered as pre-and posttest holding containers situated outside the experimental room.

On the day after the last habituation trial. the birds were asigned randomls to one of five groups of $10 \mathrm{~S}$ s each. consistins of four hock group, and one no-shock control. Immediately prior to testing. the bird ' feet and legs were dipped into a mild saline solution and a bare wire leading from one of the two terminals on a I oringer shock generator (Model 1154-MIIII was Wrapped around each leg. While being held gently by the $\mathbf{E}$. the chick then received a 2 -sec shock. timed bi a Hunter decade interial timer Model $11-5$, of 0.1 .0 . 2.0. 3.5 . or $5.0 \mathrm{mt}$. depending on group designation. l ollow ing shock termination. the leads were removed and the $S$ was immediately restrained once on its right vide for 15 sec. The duration of immobilit! " as measured with a stopwatih from the time manual restraint terminated until the chick rose to its fect

\section{Results}

The effect of different intensities of shock on duration of immobility is depicted in Fig. 1. Duration ranged from a mean of $11.4 \mathrm{sec}$ in the no-shock control group to $88^{7} .4$ sed in the group receiving a $5.0-m \mathrm{At}$ shock. Due to appreciable heterogeneity of variance. raw scores were subjected to a square-root transformation and a between-groups analysis of variance yielded a statistically significant main effect of shock $(F=36.8$ ב. $\mathrm{df}=4 / 45 . \mathrm{p}<.00 !)$.

\section{EXPERIMENT II}

In the previous experiment. using procedures more comparable to those employed by Gallup et al (1972). the effect of shock, although significant, failed to accentuate the average duration of immobility to the extent previously obtained using conditioned fear. To substantiate the effect of acquired fear, the second experiment was designed to replicate the results obtained in the 1972 study and to assess the influence of UCS intensity.

\section{Method}

The Ss consisted of 64 Production Red chicks obtained and maintained similarly to those in the first experiment.

At 21 days of age. the birds were randomly divided into four groups. With $16 \mathrm{Ss}$ per group, and fitted with plastic leg bands for jdentification purposes. Lsing the same procedure and apparatus as that employed by Gallup et al (1972). the birds were given 2 dass of habituation training in one room followed on the third day by 6 days of conditioning in a different room. with each chick receiving five trials per day.

The CS was a 40-11 light and a $65-\mathrm{dB}$ buzzer that was paired with a 1.0 .2 .0 . or $3.5-\mathrm{mA}$ shock as the UCS. Birds in the fourth group were given CS presentation without shock. During training. the onset of both light and tone occurred imultaneously and lasted for $4.5 \mathrm{sec}$. The onset of shock occurred $2.5 \mathrm{sec}$ after CS initiation and lasted for $2 \mathrm{sec}$. The intertrial interial " as randomly varied between 60 and $120 \mathrm{sec}$ with intermediate intervals of 80 and $100 \mathrm{sec}$, and each chick recived 30 conditioning trials over the 6 -day period.

So as to eliminate fear associated with extraneous cues. on the ninth day all chicks were returned to the initial room and given two additional days of habituation training in the presence of the light bulb and buzzer, but the CS $w$ as never activated.

On Das 11. as a test for the effect of conditioned tear. all birds " followed bi one 15 -sec period of manual restraint in the habituation room. The resulting duration of immobility was measured with a stopwatih from the time manual restraint ended until the thick rose to its feet.

\section{Results}

The average duration of immobility following brief confrontation with the CS is shown in Fig. 2. As can be seen. birds that had previously experienced the light and tone in association with a $3.5-\mathrm{mA}$ shock remained immobile 7.5 times longer than those given a $1.0-\mathrm{mA}$ shock during training. A simple between-groups analy sis of variance performed on a square-root transformation of these data revealed a significant main effect of LCS intensity $(\mathrm{F}=22.97 . \mathrm{df}=3 / 60 . \mathrm{p}<.001)$.

\section{EXPERIMENT III}

Comparing the data from the second experiment with 


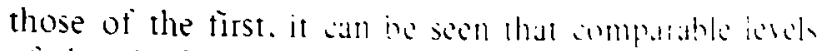

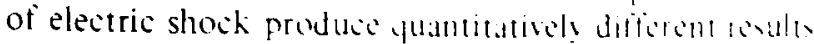
on tonic immobility. depending on whothes bakh is given prior to induction or whethes as stmulus provinuls paired with shosk is presented withoul shost ant the test trial. For instance. the mean durstion of immohilus obtained in Experiment I using a $3.5 \mathrm{~mA}$ shcik was $590.4 \mathrm{sec}$. whereas in the second experiment a CS associated with the same intensity of shock produced an average of 1.591 .3 sei of self-paced immobilit!. (ir a reaction that lasted almost three times longer.

In spite of the - day retention interval between training and testing in Experiment II. one possible objection to this comparison might be that the effect of repeated shocks during training may somehow have cumulative effects. To circumvent this problem. a third experiment employing two tear conditioned groups was conducted. On the test trial. one group received CS-only presentation prior to induction and the other was given shock.

\section{Method}

The Ss consisted of an additionsl ot itright-run Production Red chickens obtained and maintained vinilarls to those in the previous experiment.

At 3 weeks of age the bird were titted with leg band, and divided randomls into four group of 16 bird ath. [ sing the same apparatus and procedure employed in L periment ll. all birds were given 2 das of habituation training followed by 6 day's of conditioning. Birds in one group wire given (S-only presentation during training as a venitization control. In the second group, chick received 30 prexentations of the CCS onls $13.5-\mathrm{mAt}$ hocki as at picudoconditioning control. Birds in the remaining two groups were given conditioned fear training. using the conpound CS aciompanied by a 3.5-mA shoik for 30 trials. Following truining. thicks in all groups received 2 additional days of habituation.

On Day 11 the birds in the CS-only group. the LCS-only group. and one of the conditioning groups were all attached to the leads running from the shock generator and given one 4.5 -sec

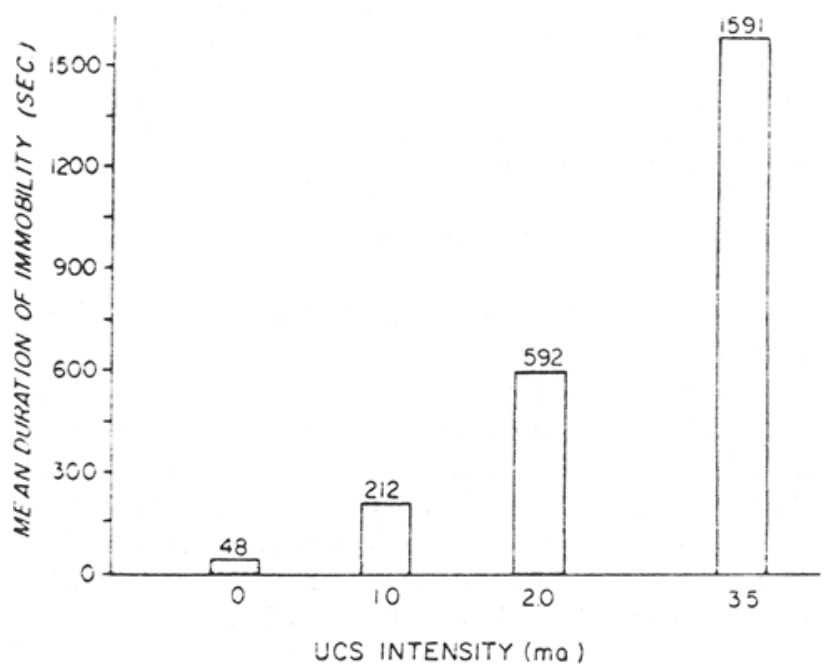

Fig. 2. Duration of immobility following brief exposure to a compound conditioned stimulus as a function of the intensity of the unconditioned stimulus in effect during training.
Table 1

Means and Standard Deviations of the Duration of Tonic Immobility as a Function of Training Conditions in Effect Prior to Testing

\begin{tabular}{lcccc}
\hline & $\begin{array}{c}\text { CS } \\
\text { Only }\end{array}$ & $\begin{array}{c}\text { UCS } \\
\text { Only }\end{array}$ & CS-LCS & CS-UCS* \\
\hline Wian & 51.19 & 250.13 & 1601.44 & 869.88 \\
SI) & 107.45 & 217.14 & 1318.44 & 880.67 \\
\hline
\end{tabular}

*iiven lCS presentotion on the test trial.

presentation of the CS alone prior to being tested for tonic inmohility. Birds in the remaining conditioned fear group were given a 2-sc $3.5-\mathrm{mA}$ hock. Without CS presentation. immediately prior to testing.

\section{Results}

The results of the third experiment are summarized in Table 1. Inspection of these data shows that the effect of CS presentation for chicks given conditioned fear tranning was appreciably different from the effect of LCS presentation on comparably trained birds, with the birds in the former group remaining immobile an average of over $700 \mathrm{sec}$ longer than those in the latter. For purpuses of analysis. the data were subjected to a square-root transfornation and a simple between-groups analysis of variance provided evidence for a significant difference between the four treatment conditions $(\mathrm{F}=3.3 .38 . \mathrm{df}=3 / 60, \mathrm{p}<.001)$. Using Duncan's multiple-range test to make individual comparisons, the mean duration of immobility for conditioned birds given CS presentation on the test trial was shown to be significantly greater $(p<.01)$ than that obtained for conditioned chicks given UCS presentation before induction.

\section{DISCUSSION}

By way of replicating previous findings (Gallup et al, 1970), habituated chicks in Experiment I given different intensities of preinduction shock showed immobility times that were linearly related to shock level. However, even strong preinduction shock failed to accentuate immobility duration to the extent previously obtained (Gallup et al, 1972) using brief exposure to a conditioned fear stimulus.

In the second experiment, aversive conditioning again proved to be more effective than shock as a means of prolonging the immobility episode. Moreover, using the duration of immobility as an index of the amplitude of conditioned fear, a significant UCS intensity effect was obtained.

Based on data from the first two experiments, it would appear that the same intensity of shock yields quantitatively different results, depending on whether it is presented prior to induction or whether a CS previously paired with shock is used on the test trial. The tenability of this suggestion. however. might be questioned on the grounds that successive exposure (1) 
shock could produce cumulative effects that are still present 2 days later on the test trial. To circumvent this possible bias. the third experiment was conducted using two groups of conditioned birds. On the test trial. one group was presented with the CS alone prior to induction, the other was given the UCS only. In support of the previous data. chicks given CS confrontation on the test trial remained immobile significantly longer than those actually subjected to electric shock.

To the extent that tonic immobility in chickens represents a reliable index of fear, the present findings could tentatively be taken to imply that the anticipation of shock may be more aversive than the actual receipt of shock. Alternatively. since the test for immobility occurs at the conclusion of a given fear manipulation, it could be argued that the greater effect of the CS over a UCS on the test trial in Experiment III might be an artifact of the conditioning procedures. For example, during training the CS was always followed by shock, but shock was consistently followed by a nonshock interval of about $90 \mathrm{sec}$ : thus. any residual fear of the UCS might be offset by the fact that shock termination signaled a brief safety period. If this were true, however, one would expect untrained birds to remain immobile much longer following their first exposure to shock. since shock offset would not be associated with danger reduction. Yet. a comparison of the data obtained in Experiment I with those of the third experiment reveals that birds without previous shock experience remain immobile no longer following a single 3.5 . or even a 5.0-mA shock than the Ss with a past history of aversive conditioning.

Since all of these experiments involved inescapable shock, another possible account of the present findings is provided by the notion of learned helplessness (e.g. Selignan. Maier. \& Solomon. 1971). Since the first experiment involved the administration of only one shock, whereas the second experiment involved multiple inescapable shocks. the notion of learned helplessness might be seen as an attractive interpretation of the enhanced levels of immobility found in the second study. However. in the last experiment the procedures obviate learned helplessness as being a viable explanation of the results. In the final experiment. all $\mathrm{Ss}$ in both conditioning gloups received an equal number of training trials entailing inescapable shock. yet on the test trial substantial differences were obtained as a result of CS vs UCS controntation.

On the other hand. perhaps the visceral and motorio consequences of CS or UCS presentation are sufficiently different to give rise to changes in the immobility episode. For example. Obrist (1968) finds both increases and decreases in somatic activity under different conditions of aversive conditioning. However. the changes noted by Obrist are so transient that it is difficult to see how thes could account for immobility reactions lasting for $30 \mathrm{~min}$ or more. It is interesting 10 note that before imposing manual restraint on the test trial in Eyporments Il and lil. shicts mesented with iho
CS reacted essentially the same as those receiving shock (i.e., in both instances there were vigorous escape attempts accompanied by wing flapping. loud vocalizations. and frequent defecation). Thus, the motoric consequences of CS confrontation would seem to fall short of providing an adequate account of these findings.

Although it could still be argued that the motoric consequences of electric shock serve to goad the animal into action and. therefore. attenuate immobility time by eliciting incompatible responses. the data consistently fail to support this contention. Whereas the shock disruption hypothesis would predict briefer immobility reactions. preinduction shock has been consistently shown to prolong the response (e.g., Gallup. Creekmore. \& Hill, 1970). Moreover. if shock produces motoric reflexes that compete with immobility. ther strong shock ought to produce more involvement and correspondingly briefer reactions than weak shock: but in Experiment I. increasing intensities of shock produced progressively longer rather than shorter immobility times. It is also important to note that the application of shock alway's preceded the induction procedure and therefore. momentary reflexive responses to shock would have dissipated by the time immobility obtained.

A final interpretive question relates to data on the predictability of shock. Under some conditions. Ss have been shown to prefer signaled to unsignaled shock (Lockard. 1963). Seligman et al (1971) contend that an organism experiences "chronic fear" under conditions of unpredictable shock, while predictable shock is said to result in less total fear. Within the context of the present discussion. the reason continued exposure to unsignaled shock might be more aversive than shock accompanied by a warning signal is because repeated experience with unsignaled shock produces a state of constant anticipation. whereas signaled shock would lead only to anticipation contingent upon presentation of the warning signal. Thus, the anticipation hypothesis predicts that the degree of aversion is (within limits) a function of the length or duration of shock anticipation. Given that the receipt of a single unpredicted shock represents the absence of shock anticipation and that repeated exposure to unpredicted shock results in a state of chronic anticipation, signaled shock should be more aversive (due to the addition of brief anticipation) than a single unpredicted shock but less aversive than situations producing chronic anticipation. By way of explaining the results of Experiment III. the UCS-only group with a previous conditioning history experienced shock on the test trial without any accompanying anticipation. whereas confrontation with a CS previously paired with shock would be expected to produce shock anticipation and a corresponding increase in tonic immobility.

\section{REFERENCES}

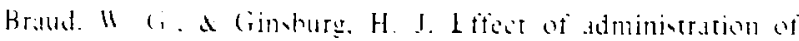

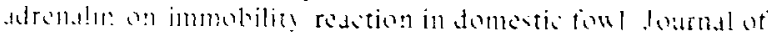




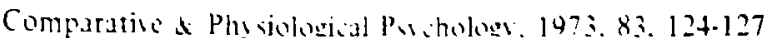

Gallup. G. G.. Jr. Creckmore, H S.. \& Hill. II. L.. III. Shockenhanced immobilits fedetions in shickens: Support for the iear hypothesis. The Puthologieal Record. 1970. 20. $243-245$.

Gallup. G. G.. Jr.. Nash. R. I .. \& Brown. C. W. The affect of a tranquilizer on the immobility rastion in shikens: tdditional support tor the iear hypothesis. Psichonomic Science. 1971.23.127.128.

Gallup. G. G.. Jr.. Nash. R. I .. Donegan. I. H.. \& MaClure. M. $K$. The immobility respons: f redator-induced reaction in thickens. The Psichologial Record. 1971. 21.513-519.

Gallup. G. G.. I T.. Nash. R. F.. Potter. R. I.. \& Donesan. X. H. Effest of urying conditions of fear on immotility reactions in domestic chickens (Gallus gallus). Journal of Comparative \& Phy siological Psichology. 1970. 73.442-445.

Gallup. G. G.. Ir.. Nash. R. 1..\& Wa!ner. A. M. The tonic immobility reaction in chicken. Renfonse characteristics and methodology: Behavior Rexarch Methods \& Instrumentation. 1971 . 3. 237-239.

Gallup, G. G.. Jr.. Rosen. T. S., \& Brown. C. W. Effect of conditioned fear on tonic immobility in domestic chickens. Journal of Comparative \& Phy siological Psychology. 1972. 78. 22-25.

Gallup. G. G.. Jr.. \& Williamson. G. T. Effect of food deprivation and a visual cliff of tonic immobility. Psychonomic Science, 1972. 29. 301-302.

Gilman. T. T.. Marcuse. F. L.. \& Moore. A. L. Animal hypnosis: A study of the induction of tonic immobility in animals. Journal of Comparative \& Physiological Psychology. 1950, 43, 99-111.
Klemm. II. R Viuruphu iologit studies of the immobilin rettes 1"animal hypnows" "I. In S. Lhrenpreis and O. (. Solnitzk! 1Ld.). Vourosciences research. Vol. 4. New rork: Academi Press. 1971

Lockard. I. S. Choic of a warning signal or no warning signal in un unavoidable thock situation. Journal of Comparative \& Phy viological Psichology. 1963. 56, 526-530.

Maver. I. D.. Giallup. G. G.. Jr., \& Bamhill. R. Conditioned inhibition and tonic immobility: Stimulus control over an innate fear response in the chicken. Journal of Comparative \& Phisiological Pachology. 1973.83.128-133.

Obrist. P. A. Heart rate and somatic-motor couplings during Adrsical atersive conditioning in humans. Journal of Experimental Psychology, 1968,77, 180-193.

Ratner. S. C. Comparative aspects of hypnosis. In J. E. Gordon (Ed.). Handbook of clinical and experimental hypnosis. New York. Macmillan. 1967.

Salzen. 1. 1. Imprinting and the immobility reactions of domestic towl. Animal Behariour. 1963. 11. 66-71.

Seligman. M. I. P.. Maier. S. F. \& Solomon, R. L. Lnpredictable and uncontrollable arersive events. In F. R. Brush (Ed.). Alersile conditioning and learning. New lork: Academic Press, 1971.

(Received for publication March 15. 1973; revision received May 1. 1973: accepted May 7. 1973.) 